\title{
Special Issue on Asset Price Dynamics and Risk Management
}

\author{
Yin-Wong Cheung \\ University of California, U.S.A.
}

When invited to prepare the special issue, I recommended to consider a broad range of topics and settled on "Asset Price Dynamics and Risk Management." The response to the call for papers for the special issue was very encouraging. Submissions were received from Asia, Australia, Europe and the U.S. In the end, we have included six high quality manuscripts in the special issue. All accepted manuscripts went through the double-blinded review process. The rest of the introduction contains a summary of each manuscript.

The accepted manuscripts cover a wide range of topics. In Exchange Rate Returns Standardized by Realized Volatility Are (Nearly) Gaussian, Andersen, Bollerslev, Diebold, and Labys examine the distributional properties of the U.S. dollar exchange rates against Deutsche mark and Japanese yen. It is well known that high-frequency asset returns (including those standardized by GARCH variance estimates) are non-normal. The authors demonstrate that exchange rate returns standardized by the realized volatility measure, which involves the sum of intraday high-frequency returns, are very nearly normal. The construction of nearly normal asset return data has significant implications for both academics and practitioners since normality is a crucial assumption in modelling high frequency volatility, out-of-sample forecast analysis, asset pricing, and risk management.

Corporations domiciled outside the U.S. can have their shares traded

\footnotetext{
*Many people contributed to the completion of the special issue. Undoubtedly, the authors played a central role in the whole process, and I would like to thank them for their contributions. I also would like to thank Peter Theodossiou, the Managing Editor, for his continuous support and encouragement throughout the whole process. Anna Shnayder's professionalism and reliability made my life as the Guest Editor much easier. Last, but not the least, I would like to thank all the referees for their valuable comments, suggestions, and timely services.
}

(Multinational Finance Journal, 2000 vol. 4, no. 3\&4, pp. 155-157)

(CMultinational Finance Society, a nonprofit corporation. All rights reserved.

DOI: $10.17578 / 4-3 / 4-1$ 
in the U.S. market as American Depository Receipts (ADRs). Hertzel, Lowengrub, and Melvin, in Information, Announcement, and Listing Effects of ADR Programs and German-U.S. Stock Market Integration, examine the effects of listing as an ADR. Intradaily stock prices of individual German firms that are traded as ADRs are used to study the filing, announcement, listing, and volume effects. The filing effect is found to be always associated with a positive abnormal return. However, both positive and negative abnormal returns are identified with the announcement and listing effects. Further, the trading volume in the home market can increase or decrease as a result of ADR listing. The results suggest that the effects of trading as an ADR are firm-specific.

Yang, in An Integrated Risk Management Method: VaR Approach, proposes a procedure to calculate the value at risk $(\mathrm{VaR})$ of a portfolio that is affected by market risk, credit rating change, and default risk. Some results in actuarial science are used to construct the integrated risk management framework. The ruin theory provides a major building block of the analysis. Under the stated assumptions, Yang derives analytical solution to the VaR problem and uses numerical examples to illustrate the method. As it stands, the procedure is based on some simplifying assumptions and is quite demanding on computing resources. The exercise, however, offers a good starting point for investigating the practical problem of integrated risk management.

For academia, a market crash can be an exceptional opportunity to investigate certain finance issues. In the first paper (Investor Recognition of Bankruptcy Costs: Evidence from the 1987 Stock Market Crash), Eun and Jang exploit the information from the 1987 market crash to assess the significance of bankruptcy costs. It is perceived that the probability of bankruptcy increases during the crisis period. If bankruptcy costs are significant, then their effects should be magnified and reflected in stock prices during the crash period. Controlling for size and industry effects, Eun and Jang find that individual firms' bond ratings and their post-crash cumulative abnormal returns are negatively related. As the potential bankruptcy cost is reflected in bond ratings, the results suggest that investors recognize the bankruptcy cost and the cost is significant.

In High Frequency Deutsche Mark-U.S. Dollar Returns: FIGARCH Representation and Non-Linearities, Baillie, Cecen, and Han study the long memory property of the dollar-mark exchange rate volatility. Specifically, the fractionally integrated GARCH model is fitted to both intradaily and daily data. The long memory parameters estimated 
from different data frequencies are quite similar and, thus, are suggestive of the return volatility is generated by a self-similar process. The diagnostic test results indicate that the fractionally integrated GARCH model provides an adequate description of the data dynamics. In sum, the empirical evidence is supportive of the view that long memory volatility is an intrinsic property of the dollar-mark exchange rate series.

The notion of greater China has attracted considerable attention since China began its economic reform in the early 1980s. Lo and Chan, in Diagnosing Shocks in Stock Market Returns of Greater China, examine the behavior of daily returns on the four Greater China stock markets - Hong Kong, Shanghai, Shenzhen, and Taiwan. Using a joint estimation procedure, Chan and Lo identify the occurrences of outliers (large shocks) and find that large shocks are quite common in these stock market return series. The outlier patterns are different across the market. For the Hong Kong market, the outliers cluster around the 1997 financial crisis period and the government invention conducted in 1998. For the other markets, the outliers are usually related to local events. The difference in return patterns provides some hints for portfolio diversification.

\section{References}

Anderson, T.; Bollerslev, T.; Diebold, F.; and Labys, P. 2000. Exchange rate returns standardized by realized volatility are (nearly) Gaussian. Multinational Finance Journal. 4(3\&4): 159-179.

Ballie,R.; Cecen, A.; and Hang, Y. 2000. High frequence Deutsche mark- U.S. dollar returns: FIGARCH representations and non linearities. Multinational Finance Journal. 4(3\&4): 247-267.

Eun, C. and Jang, J.2000. Investor recognition of bankruptcy costs: Evidence from the 1987 market crash. Multinational Finance Journal. 4(3\&4): 221245.

Hertzel, M.; Lowengrub, P.; Melvin, M. 2000. Information, announcement, and listing effects of ADR programs and German-U.S. stock market integration. Multinational Finance Journal. 4(3\&4): 181-200.

Lo, W.C. and Chan, W.S. 2000. Diagnosing shocks in stock market returns of greater China. Multinational Finance Journal. 4(3\&4): 269-288.

Yang, H. 2000. An integrated risk management method: VaR approach. Multinational Finance Journal. 4(3\&4): 201-219. 